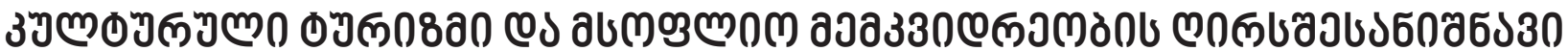

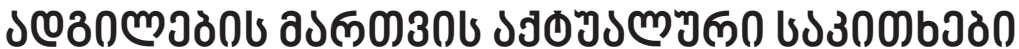

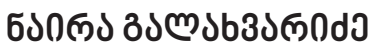

https://doi.org/10.35945/gb.2017.03.028

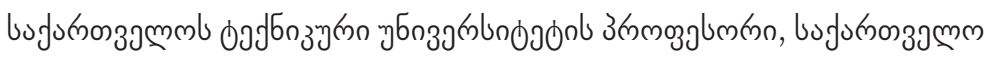

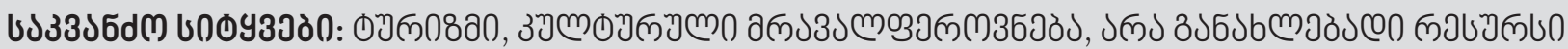

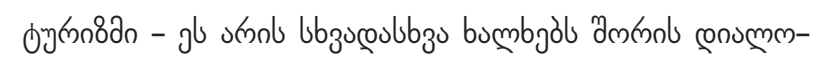

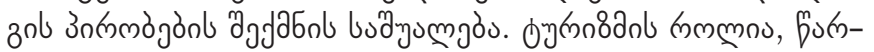

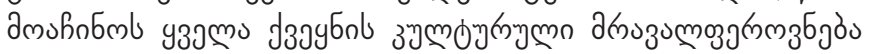

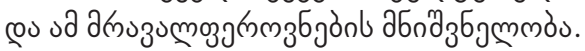

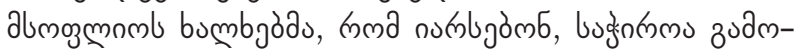

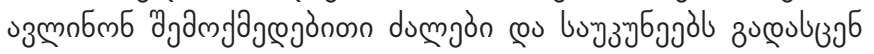

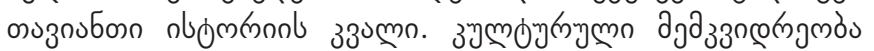

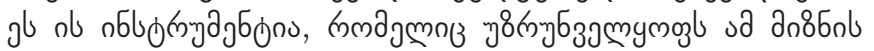

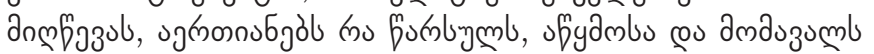

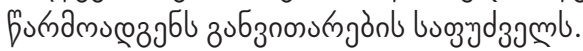

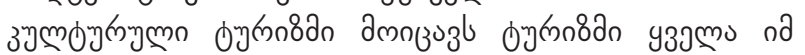

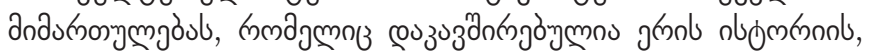

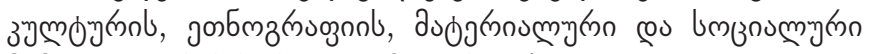

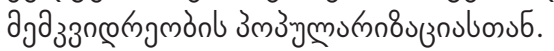

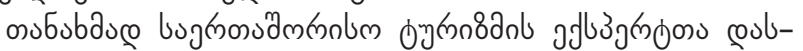

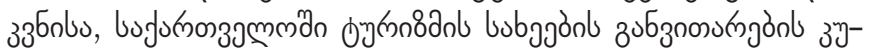

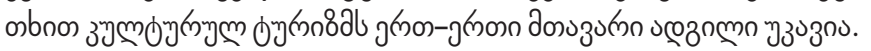

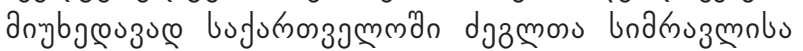

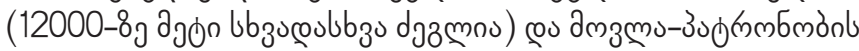

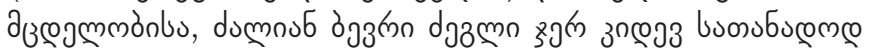

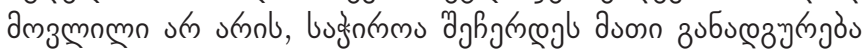
cu n

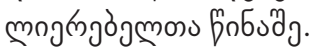

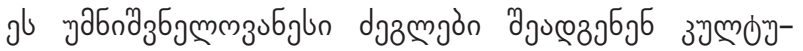

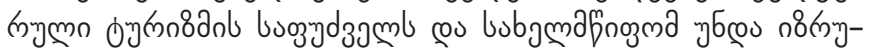

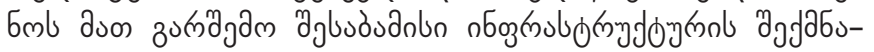
amfुum

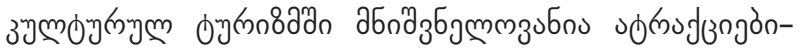

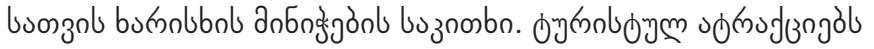
כm

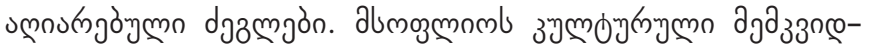
mgmòn co

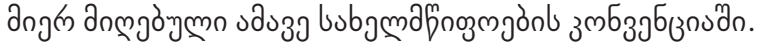

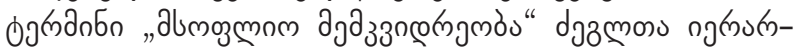

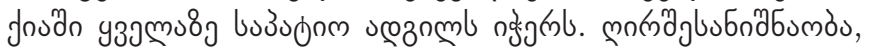

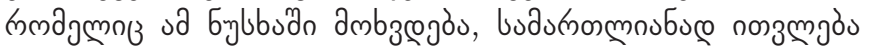

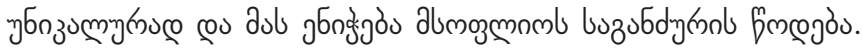

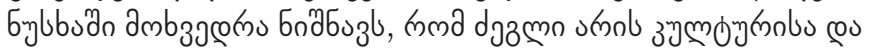

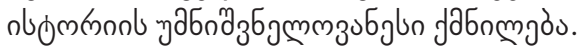

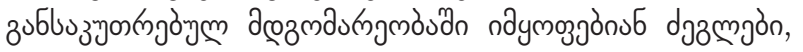

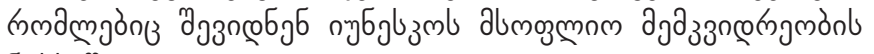
Бฤibudn.

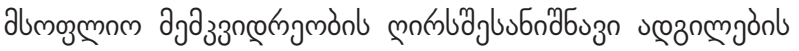

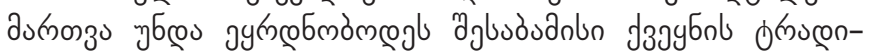

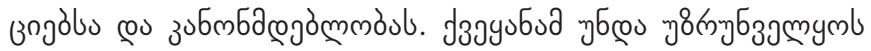

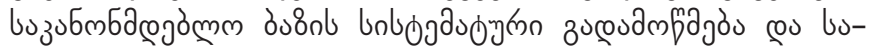

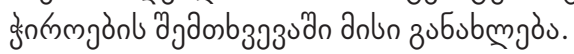

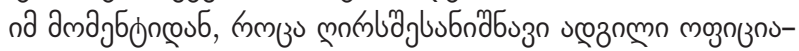

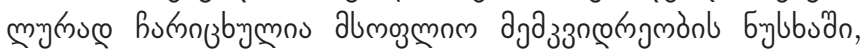

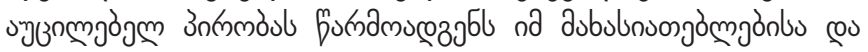

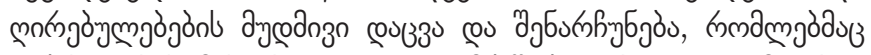

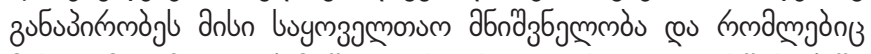

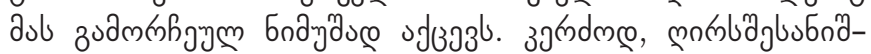

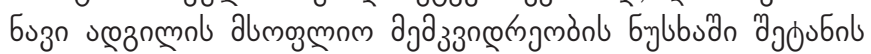

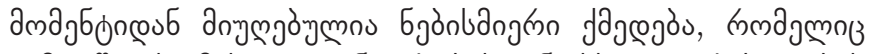

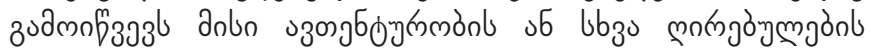

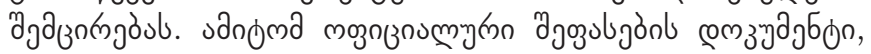

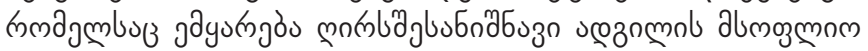

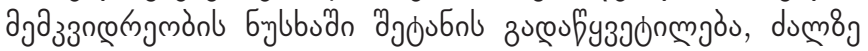

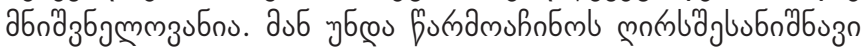

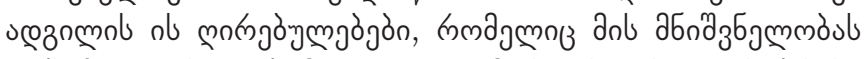

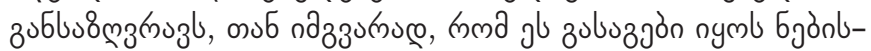

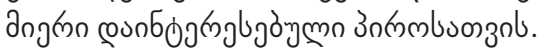

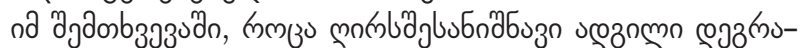

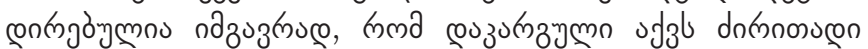

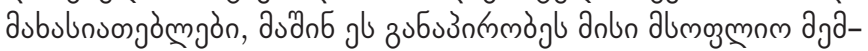

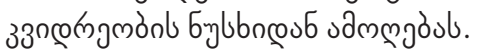

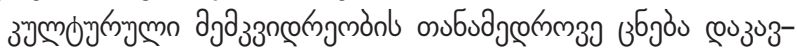

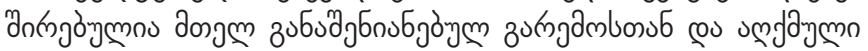
चб

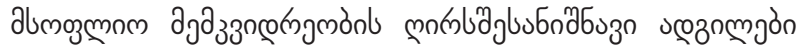

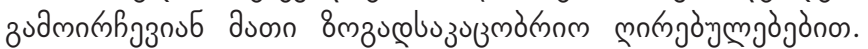

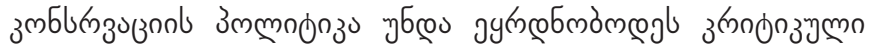

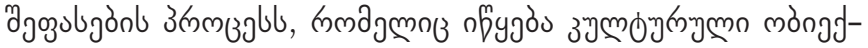

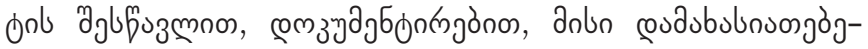

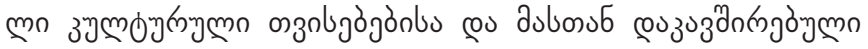

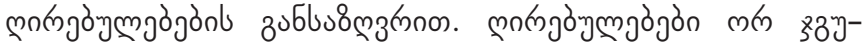

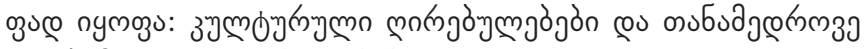

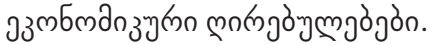

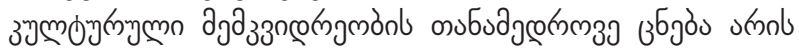

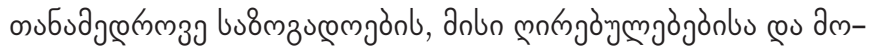

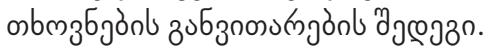

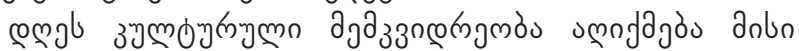

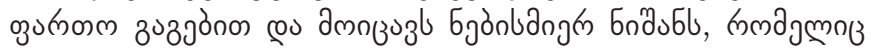

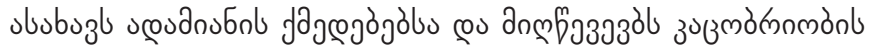

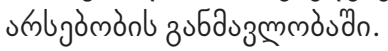

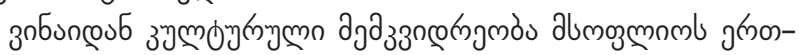

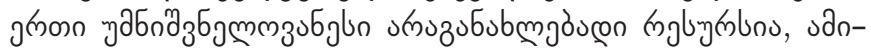




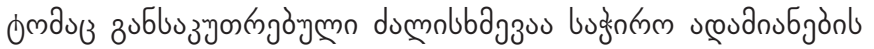

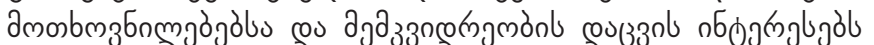

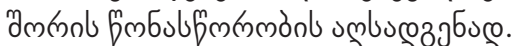

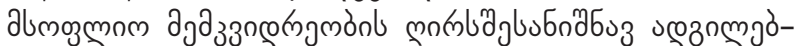

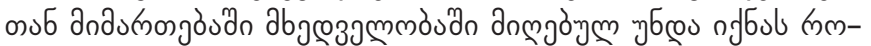

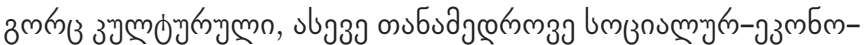

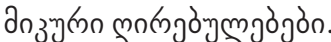

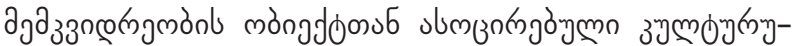

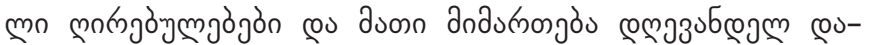

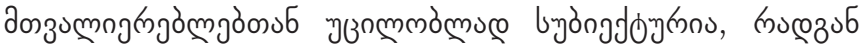

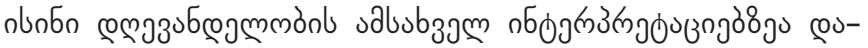

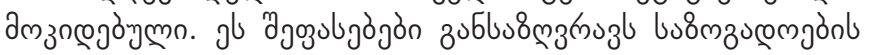

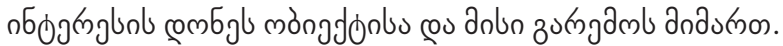

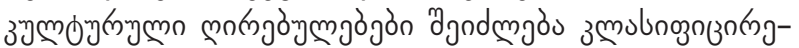

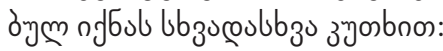

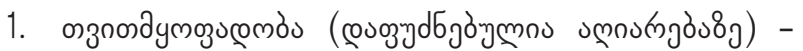

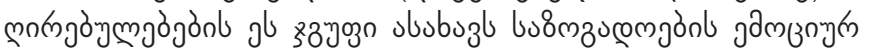
उ०3

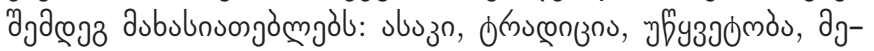

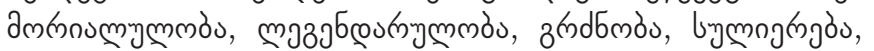

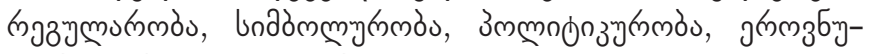

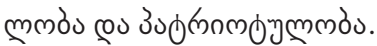

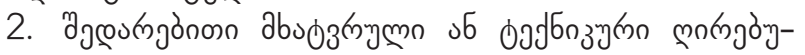

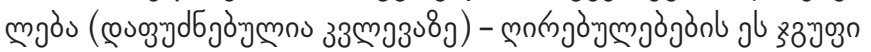

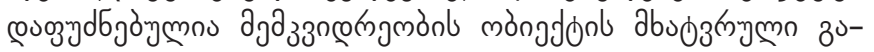
coufysadol, anlo osd

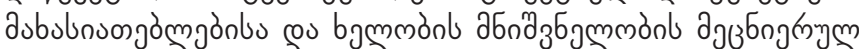

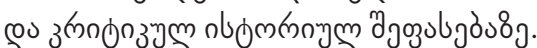

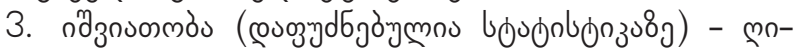

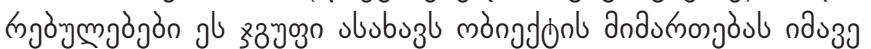

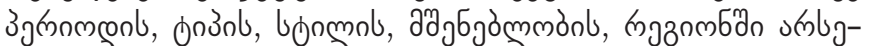

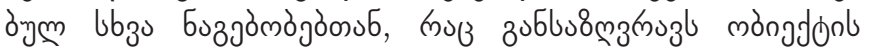

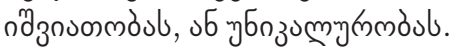

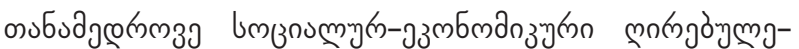

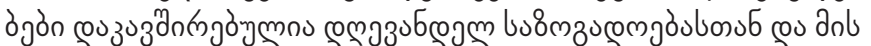

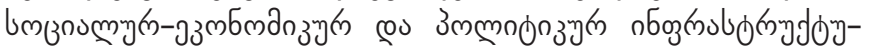
molbosob.

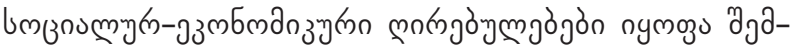

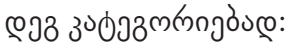

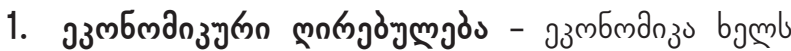

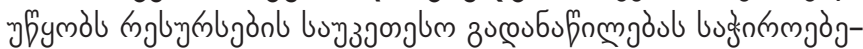

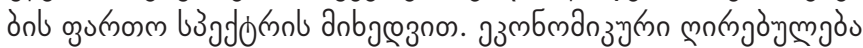

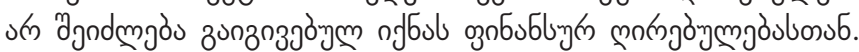

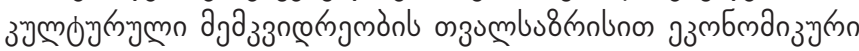

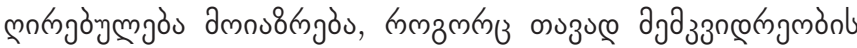

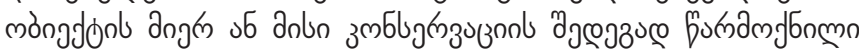

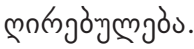

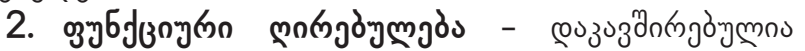

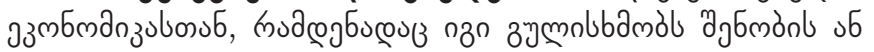

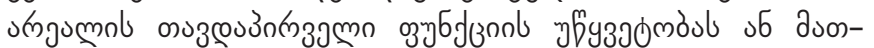

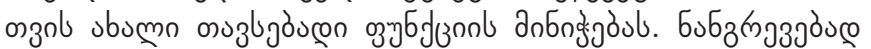

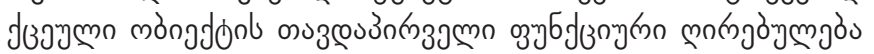

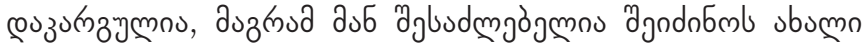

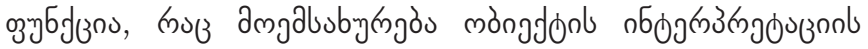

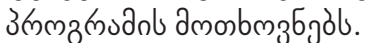

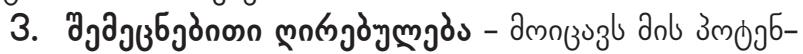

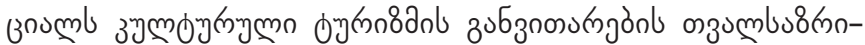

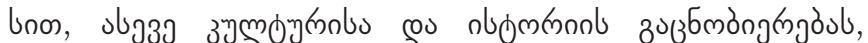

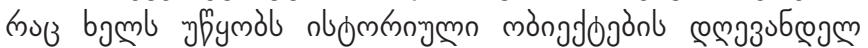

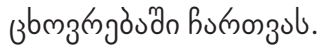

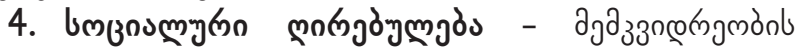

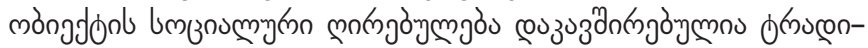

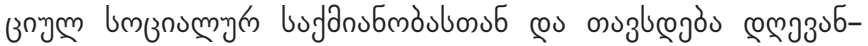

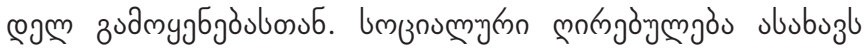

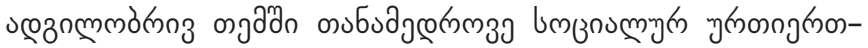

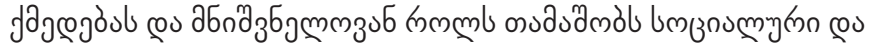

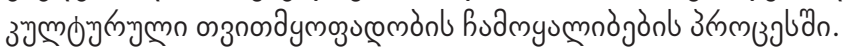

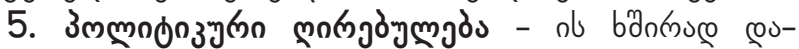
उ०3

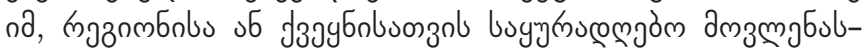

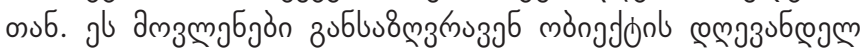

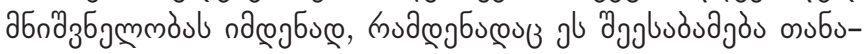

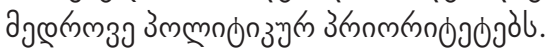

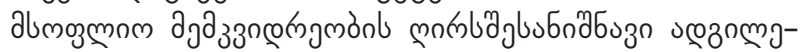

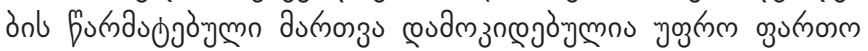

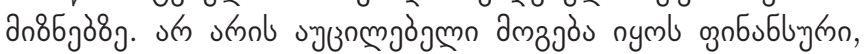

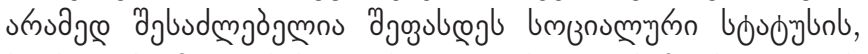
उ

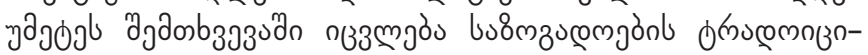

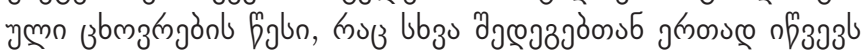

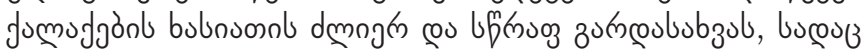

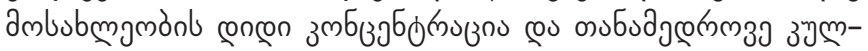

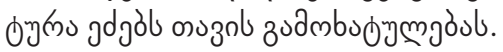

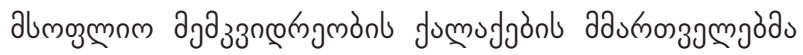

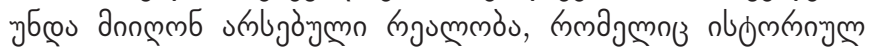

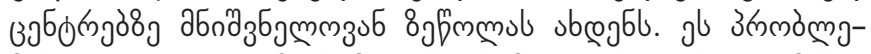

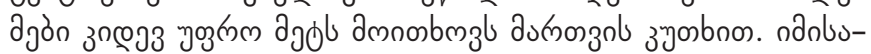

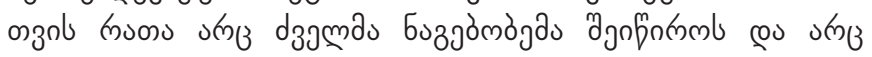

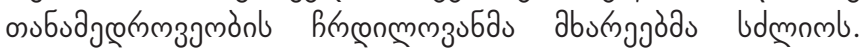

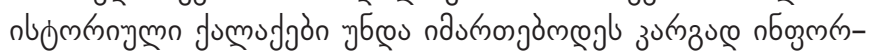

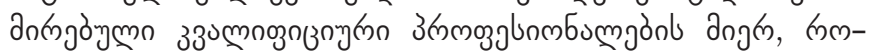

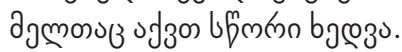

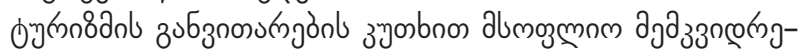

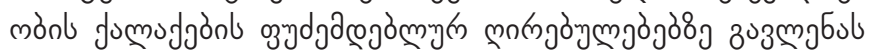

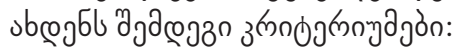

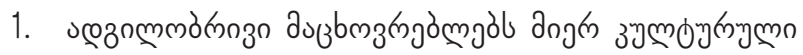

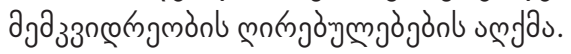

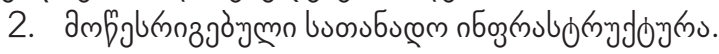

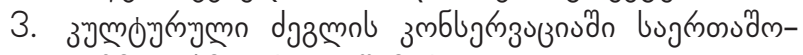

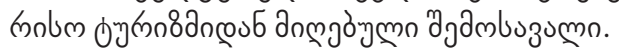

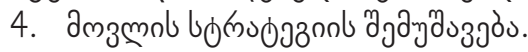

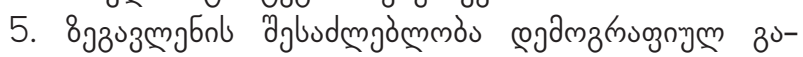

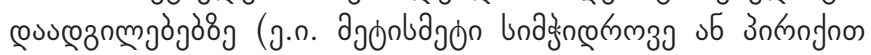

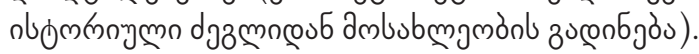




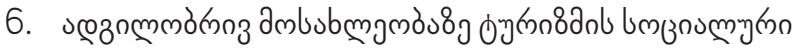
зงзм่อง.

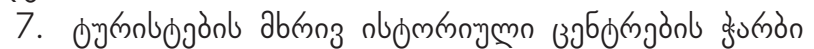

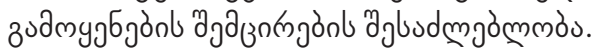

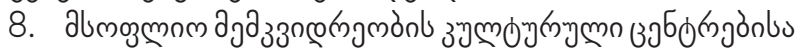

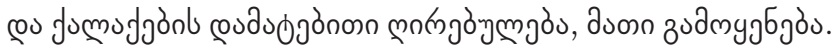

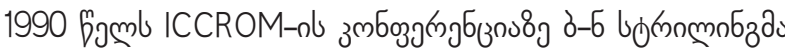

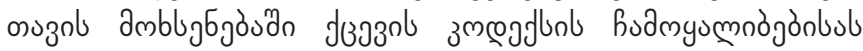

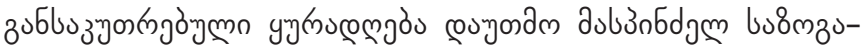

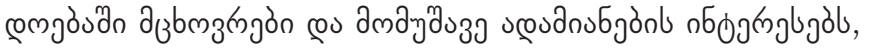

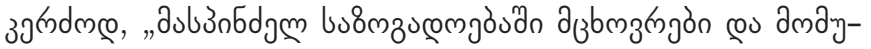

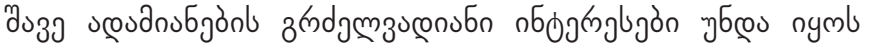

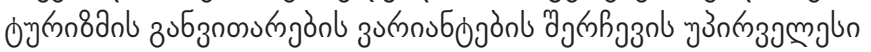

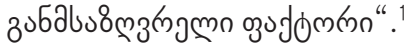

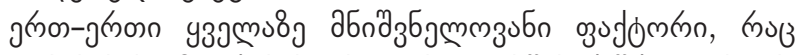

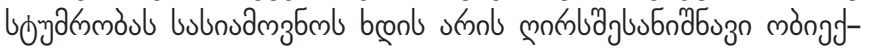

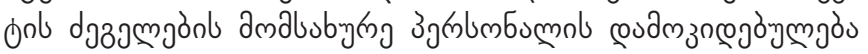

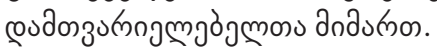

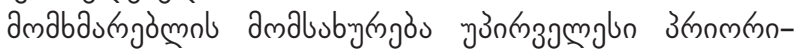

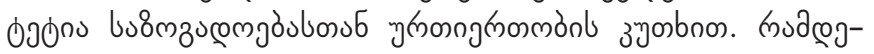

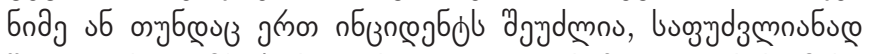

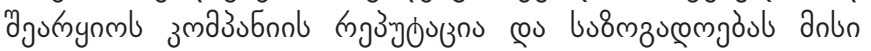

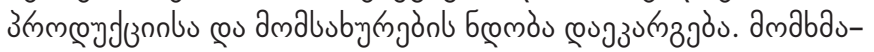

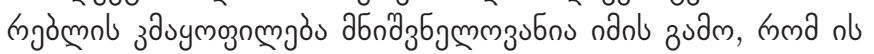

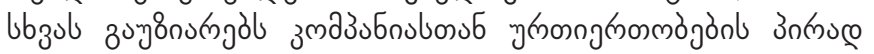

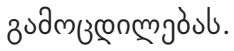

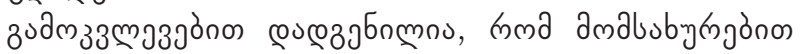

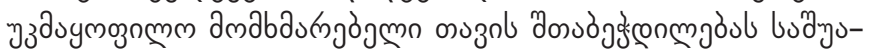

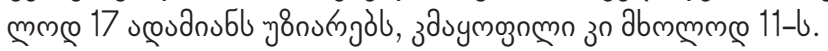

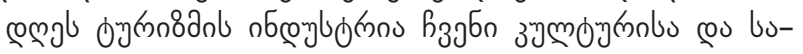

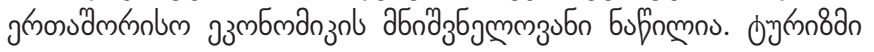

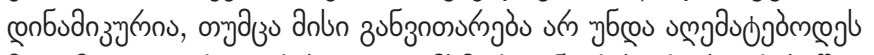

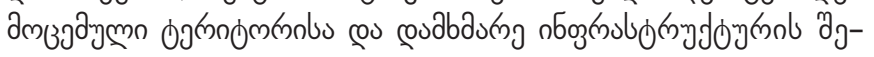

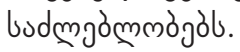

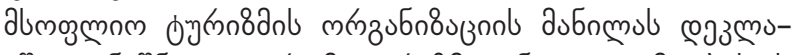

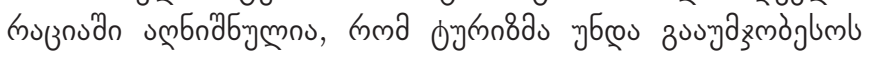

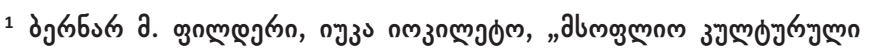

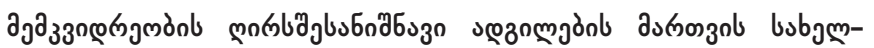

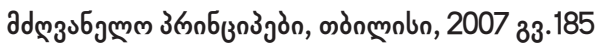

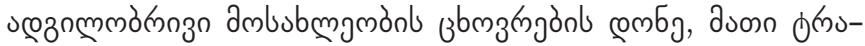

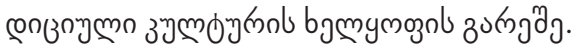

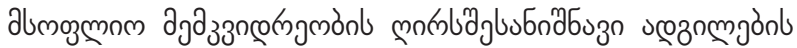

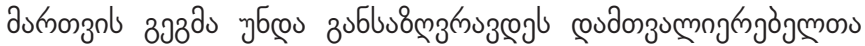

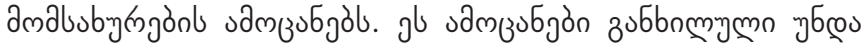

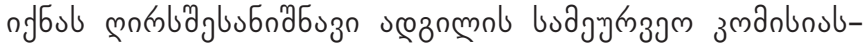

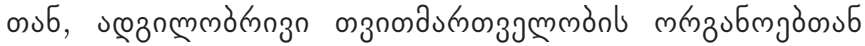

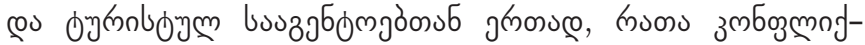

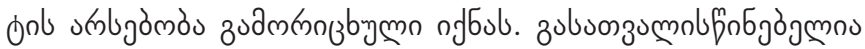

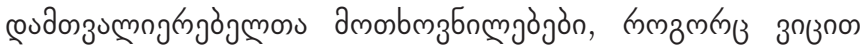

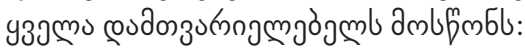

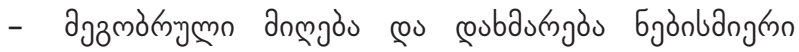

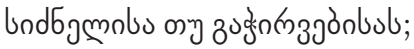

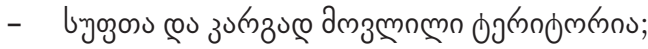

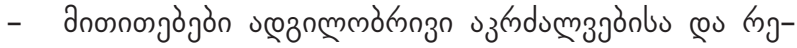

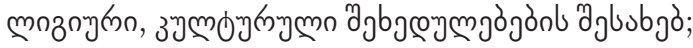

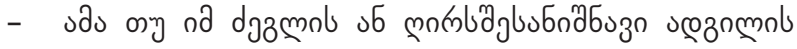

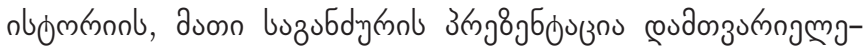

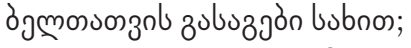

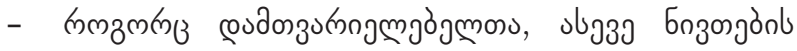

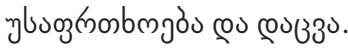

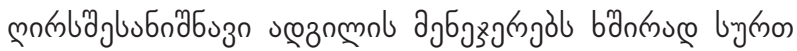

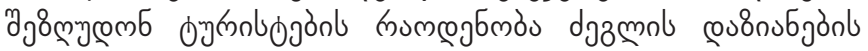

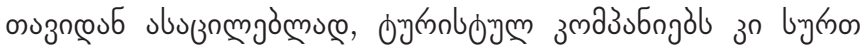

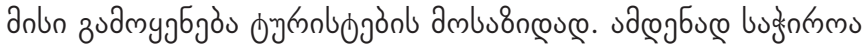

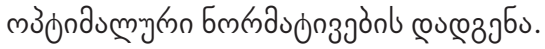

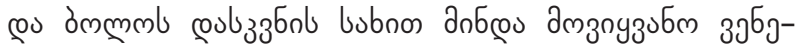

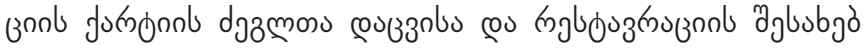

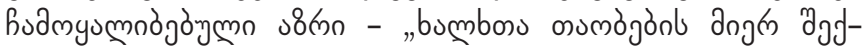

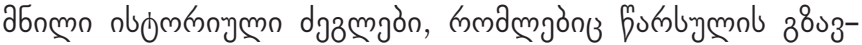

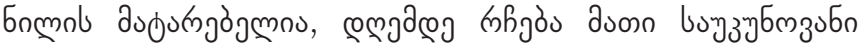

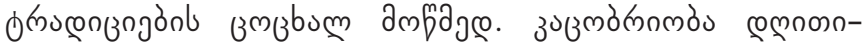

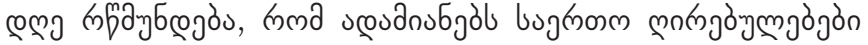

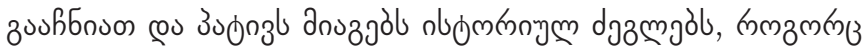

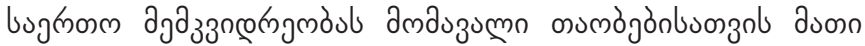

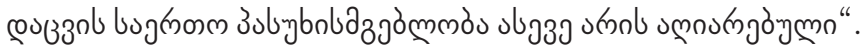

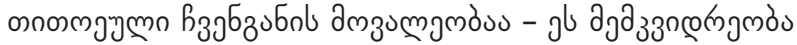
anbn sзолб

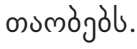

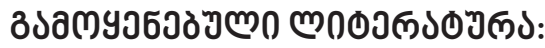

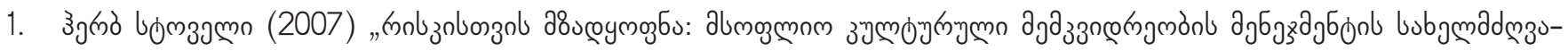
бэmल" mònmolno.

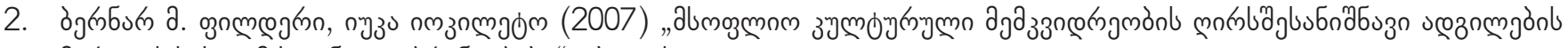

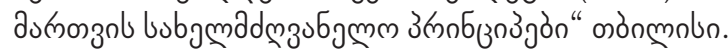

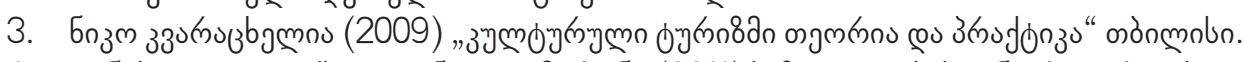

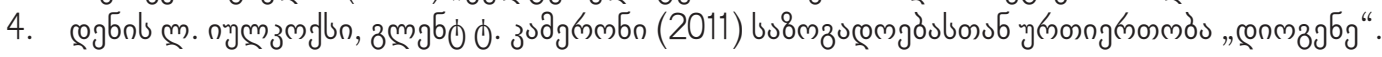




\section{CULTURE TOURISM AND ACTUAL ISSUES OF THE MANAGEMENT OF REMARKABLE WORLD HERITAGE SITES}

NAIRA GALAKHVARIDZE

https://doi.org/10.35945/gb.2017.03.028

Professor of Georgian Technical University, Georgia

\section{KEYWORDS: TOURISM, CULTURAL DIVERSITY, NOT A RENEWABLE RESOURCE}

\section{SUMMARY}

The article is about importance of the landmarks and monuments in cultural tourism and it gives the specific information how to run management of such places.

The term "World Heritage" has the most important place in the hierarchy of monuments. The landmark or the monument, which happens to be on the list is rightly considered to be unique and it is assigned the rank of the world's treasure and it means, that the landmark or the monument is the most important thing of culture and history.

Once the monument is included in the "UNESCO World
Heritage" list the country should provide to check the legislative base systematically and to renew it if necessary.

It is very important to protect and keep the monument's the characteristics and value that were the crucial points in recognizing the above mentioned place to be authentic and important for the mankind.

In case of damaging the monument that is in the World heritage list the monument is immediately taken from the list.

It's our duty to take care of the places of such great importance in order to keep them for our future generations. 